\title{
Fertility, the Quality of Children and Economic Growth
}

\author{
Chi-Chu Chou \\ Feng-Chia University
}

\begin{abstract}
This paper develops a theory of the fertility choice that focus on the shadow price of the quality of children and fertility rate within a framework of long term economic growth. The analysis also links the shadow price of quality with the interaction between fertility and economic growth. Through the choice of per child quality within family, the analysis contributes to narrowing the many remaining gaps between endogenous family decisions on fertility and aggregate economic growth. (JEL Classification: J13, J24, 010, 049)
\end{abstract}

\section{Introduction}

Rapid economic growth in East Asia since 1970s has transformed countries such as South Korea and Taiwan from agricultural economies into industrial ones. Their outstanding performance relative to other groups of developing world has provided fruitful discussions that help revive the acad- 
emic interests in growth and development. In addition to the rapid changes in aggregate economic structure, the structure and behavior of families in these rapidly developing economies has also changed remarkably. Fertility declines and demand for more and better education increased sharply along with rising per capita income. In South Korea the total fertility rate, defined as the total births per woman during her entire reproductive period, declined from 4.3 in 1970 to 1.8 (a replacement level of population) in 1994, while in Taiwan the rate declined from 4.0 to below 1.8 during the same period. Since in the last four decades, population growth rates in Asia were among the highest in the world, the prospect of population increase has attracted considerable worry in the region. ${ }^{1} \mathrm{M}$ any policymakers and other groups often predict disastrous results of the future population growth in Asia, based on a simple relation between economic development and population growth. That is, rapid increase in population will eventually slow down economic growth. South Korea and Taiwan's remarkable population transition provides a completely different picture about the population growth in the course of economic development in Asia.

An old Chinese proverb says: More children and more grandchildren would bring more fortune to the family. Another old Chinese proverb goes: Go to study is the most valuable one among tens of thousands choices. These two traditional views of personal and family choices represent important part of the conventional Chinese family values. However, these two views have undergone completely different evolvement in almost a generation's time since the modern growth started. The former view is no long existed in any serious way, while the latter one is reinforced by economic growth. Although economic literature does not lack answers to this phenomena, the private fertility choice and many aspects of family decisions are treated as exogenous in most growth models. This paper uses the concept 
analysis nar rows the many remaining gaps between private family decisions and aggregate economic changes.

In the tradition of classical economics, Thomas M althus [1766-1834] believed that the population growth would eventually curb the economic growth. He proposed a dynamic structure of economic development, where population growth serves as the primary adjusting factor. The economy eventually settles down at an equilibrium wage rate, the so called "subsistence level". In this M althusian "endogenous" fertility model, the population grows if wage is higher than the subsistence level. Since land becomes more scare as population grows, the diminishing return of the land sets in and the wage tends to fall back to the subsistence level.

One of the stylized facts in modern economic development is the secular decline in fertility rate as a country's per capita income grows. Contrary to $M$ althus's proposition that the fertility rate would increase as family's incomes rise, the fertility rate continues to decline in most industrial world and other fast growing economies. After World War II, the Neoclassical growth model developed by Solow [1956] and Swan [1956] incorporates capital accumulation into the process of economic growth. Although they do not share with M althus's pessimistic view on the relation between population growth and living standard, their models still imply a negative implication from population growth. The neo-classical growth approach avoids the controversy of population's role in economic development by ignoring it. Population is treated as an exogenous variable.

In the last few decades economists have been trying to incorporate again the population and fertility choice into the analysis of economic growth 〈Schultz [1973]; M ichael [1973]; Razin and Ben-Zion [1975]; Eckstein and Wolpin [1985]; Rosenzweig [1990]>.2 Since the pioneering work of Becker and Lewis [1973], demand for quality and its substitution for quantity has 
of new growth theor y, human capital was treated as a crucial factor that contributes to economic growth. Another unique feature in some of these models is that: like Malthus, the population growth is an endogenously determined variable, yet unlike $M$ althus, the equilibrium level of income is not a miserable one. Only under certain conditions given in Becker, M urphy, and Tamura [1993], could a country fall into the M althusian trap equilibrium, where a very low per capita income could persist indefinitely. This multiequilibrium state explains why different regions could experience very diversified path of growth in a very long period of time.

Becker and Barro [1988] developed an intergenerational transfer models that links the decisions by different generations of the same family. They also extends the model on fertility to analyze intergenerational transfers and economic growth $\langle$ Barro and Becker [1989] $\rangle$. The latter paper appears to be the first model that combines aggregate growth with fertility choice based on parental altruism. In their model countries with higher costs of raising children have relatively lower steady-state growth rates of population. This result is derived through an indirect effect of lower interest rates. However, the cost of raising children has an element of investment that can not be distinguished directly from the concept of costs. The returns of such investment must be considered when exploring the fer tility choice and costs.

Since in the dynastic utility function, the utility of children is part of parents' utility function, on the one hand increase in the investment in human capital of children can be treated separately as a response to the rates of return to children, holding constant the parents' degree of altruism. On the other hand increase in the demand for quality of children is treated as a changing combination of the content of children demanded. Both notions view the endogenously determined fertility as a private response to changing aggregate economic conditions. Yet the interaction between the two dri- 
between quantity and quality of children, within which the equilibrium fertility rate is determined. Section III further includes family's time and effort devoted in investment in human capital, where human capital is a function of the expenditure on the quality of children. The path of per capita output growth is derived from the fertility model. Section IV concludes the paper.

\section{The Model}

In his revolutionary work on the demand for children, Becker (1993: chapter 5, enlarged ed.) generalizes the notions that parents make choice between the number and the quality of children, and using a utility function that includes the quantity and quality of children and the quantity of goods consumed by the family. The models developed by De Tray [1973] and Willis [1973] also introduce the quality dimension into the analysis of demand for children. The key to the derivation of the result is that each component in the utility function has a shadow price and these shadow prices interact with each other. Thus family changes its behavior in response to changing economic conditions, the value of time to maximize its welfare, subject to its resource constraint.

Assume that all families has $\mathrm{N}$ members at each generation. The population grows at the rate $n$, thus the number of births per unit of time is $\mathrm{nN}$ :

$$
\mathrm{N}=\mathrm{nN} \text {, }
$$

For simplicity the model assumes that the mortality rate is zero, thus $\mathrm{n}$ denotes both the bir th rate and net population growth rate. ${ }^{4}$

Using Becker's concept of the shadow prices of the "consumption", the family's income can be spent on raising children and purchasing goods:

$$
\mathrm{P}_{\mathrm{q}} \mathrm{qnN}+{ }_{\mathrm{c}} \mathrm{CN}=[\mathrm{w}+(\mathrm{r}-\mathrm{n}) \mathrm{k}] \mathrm{N}
$$


which are not related to the number of children, while other expenditures depend on the number of children. Here $\mathrm{P}_{\mathrm{q}}$ contains both parts of the expenditures on quality. The family's income consists of wage $(w)$ and rental incomes on the per capita capital k. Although wage rate differs among different age groups and should related to previous investment in human capital, here I assume that $\mathrm{w}$ is a constant. ${ }^{5}$ Also assuming that all factor mar kets are perfectly competitive, thus $w$ and $r$ are exogenously determined. The production activities will be incorporated in Section III.

The family's budget constraint can be expressed alternatively in terms of shadow prices of various "commodities," quality q, quantity of children $\mathrm{nN}$, and total consumption $\mathrm{CN}$ :

$$
\left(P_{q} n N\right) q+\left(p_{q} q\right) n N+{ }_{c} c N=[w+(r-n) k] N+\left(P_{q} n N\right) q .
$$

With different notations, the equation (3) can be written as

$$
{ }_{q} q+{ }_{N} n N+{ }_{c} C N=[w+(r-n) k] N+\left(P_{q} n N\right) q \equiv R,
$$

where $\pi_{q}$ denotes the shadow price of quality $q, \pi_{N}$ the shadow price of quantity $\mathrm{nN}$, while $\mathrm{R}$ is the value of the family's "full wealth." Since the shadow prices encompass the interactions between quantity and quality, the budget constraint is not linear. The internal equilibria exist only when the quantity and quality are not close substitutes.

The evolution of the family's per capita capital stock becomes

$$
\dot{k}=\left(\frac{1}{N}\right)\left(R-{ }_{q} q-{ }_{N} n N-{ }_{c} \mathrm{CN}\right)
$$

Assuming that the family of a given generation cares the welfare of their children, grandchildren, and later descendants. A representative dynastic family maximizes the following dynastic function: 
value Hamiltonian is

$$
\mathrm{H}_{\mathrm{c}}=\frac{1}{1-}\left(\mathrm{n} \mathrm{N}^{1-} \mathrm{cq}\right)^{1-}+{ }_{1}(\mathrm{nN})+\left(\frac{2}{\mathrm{~N}}\right)\left(\mathrm{R}-{ }_{\mathrm{q}} \mathrm{q}-{ }_{\mathrm{N}} \mathrm{nN}-{ }_{\mathrm{c}} \mathrm{CN}\right)(7)
$$

The utility maximizing head of a dynastic family weighs the marginal benefit of having more and better descendant against the net cost of producing them. These requirements are given by the first order necessary conditions $\partial \mathrm{H}_{c} \partial \mathrm{c}, \partial \mathrm{H}_{\mathrm{c}} / \partial \mathrm{q}$, and $\partial \mathrm{H}_{\mathrm{c}} / \partial \mathrm{n}$ :

$$
\begin{aligned}
& \left(\mathrm{n} \mathrm{N}^{1-} \mathrm{q}\right)^{1-} \mathrm{c}^{-}=2 c^{\prime} \\
& \left(\mathrm{n} \mathrm{N}^{1-} \mathrm{c}\right)^{1-} \mathrm{q}^{-}={ }_{2}\left(\frac{\mathrm{N}}{\mathrm{q}} \mathrm{n}\right)
\end{aligned}
$$

and

$$
\left(\frac{-}{\mathrm{n}}\right)\left(\mathrm{n} \mathrm{N}^{1-} \mathrm{cq}\right)^{1-}=-{ }_{1} \mathrm{~N}+{ }_{2}\left(\mathrm{k}+{ }_{\mathrm{N}}\right)
$$

The equations (8) and (9) give

$$
\mathrm{cN}{ }_{\mathrm{c}}=(\mathrm{qnN}) \frac{\mathrm{N}}{\mathrm{q}} \text {. }
$$

The shadow cost of consumption is equal to the change in total expenditure on quality due to the effect of changing quality on the shadow price of quantity. Thus if increase in the total quality per child raises the shadow price of the quantity of children, the shadow cost of consumption will also increase. As discussed in Becker [1993], the price of quantity shows a positive relation with q. Since the rates of return to investment in human capital increase as the economy grows, the demand for $q$ also increases. Increased demand for $q$ also raises the total shadow cost of consumption, thus holding income constant, family will substitute the expenditure on $q$ for $c$. Since $\partial \pi_{N} / \partial q=P_{q}$, the equation (11) also implies that 
the definition of $\pi_{N}$ depends on $q\left(\pi_{N}=P_{q} q\right)$. An increase in $\pi_{N}$ would lower the demand for $\mathrm{nN}$ and thus further lowers the shadow price of quality, because $\left(\pi_{q}=P_{q} n N\right)$. From the equations (9) and (10), the ratio of relative current-value shadow prices of children $\mathrm{nN}$ and per capita capital can be expressed as:

$$
\frac{1}{2}=\left(\frac{1}{N}\right)[k+(1-) \mathrm{N}]
$$

The shadow value of quantity in terms of foregone shadow value of capital is an increasing function of $k$ and a decreasing function of $\pi_{N}$, if $(1-\phi)<0$ (i.e. $\mathrm{nN}$ and $\mathrm{q}$ are not close substitutes). The second term on the right hand side is derived from the expression that $\phi q\left(\partial \pi_{N} / \partial q\right)=\phi q P_{q}=\phi \pi_{N}$, thus the interaction between the quantity and quality and their impacts on the shadow prices of quantity is indirectly expressed in the equation (13). Since $\phi q\left(\partial \pi_{N} / \partial q\right)=\phi \pi_{N}>0$, an increase in the demand for $q$ raises the relative current-value shadow price of the quantity of children.

The other necessary conditions require that the evolution of the costate variables satisfy and

$$
\begin{aligned}
& { }_{1}=-\frac{H_{c}}{N}+\quad{ }_{1}=-\left(\frac{1}{N}\right)\left(n^{1-} c q\right)^{1-}(1-)-{ }_{1} n+\quad{ }_{1}, \\
& { }_{2}=-\frac{H_{c}}{k}+\quad{ }_{2}=-(r-n)_{2}+2 .
\end{aligned}
$$

The equilibrium paths for $n, q$, and $c$ can be solved from the above system. Since the solutions to the equilibrium paths are excessively tedious in this formulation, the analysis here will focus on the balanced growth path. Since the maximum principle gives that $\dot{\lambda}_{1}=0$ and $\dot{\lambda}_{2}=0$ at steady state. Thus by using the conditions that the costate variables have the same growth rates $\left(\dot{\lambda},\left|\lambda=\dot{\lambda}_{-}\right| \lambda=0\right)$ in a balance arowth eauilibrium. the followina relation 
growth in consumption is

$$
\frac{\dot{\mathrm{c}}}{\mathrm{c}}=\frac{\dot{\mathrm{k}}}{\mathrm{k}}=\frac{1}{\mathrm{k}}\left[\mathrm{w}+(\mathrm{r}-\mathrm{n}) \mathrm{k}-{ }_{\mathrm{N}} \mathrm{n}-{ }_{\mathrm{c}} \mathrm{c}\right]
$$

Thus the growth rate of consumption becomes

$$
\frac{\dot{\mathrm{C}}}{\mathrm{c}}=\left(\frac{1}{{ }_{1} \mathrm{~N}}\right)\left(\mathrm{n} \mathrm{N}^{1-} \mathrm{cq}\right)^{1-}(1-)+\frac{\mathrm{n}}{-}-.
$$

Substituting the equations (8), (10) and (13) into the above equation, the costate variables can be eliminated:

$$
\frac{\dot{c}}{\mathrm{c}}=\left(\frac{1}{\mathrm{~N}}\right) \frac{{ }_{\mathrm{q}} \mathrm{q}(1-)}{\mathrm{k}-(-1){ }_{\mathrm{N}}}+\frac{\mathrm{n}}{-}-
$$

Solving the system explicitly involves extremely arduous works. Instead, the following analysis chooses the expression for $n$ derived from the steady state condition. ${ }^{6}$ By using the equations (19) and (17) the fer tility $n$ can be expressed as

$$
n=\frac{\left(w+r k-{ }_{c} c\right) N\left[(-1)_{N}-k\right]+{ }_{q} q(1-) k-k}{[(1+) k+N]\left[(-1)_{N}-k\right] N}
$$

From the expression for $n$, the per capita family income $(w+r k)$ is positively related to the fertility. Therefore, the income effect of demand for quantity is positive and children is a "normal good" is this formulation.

$M$ althusian model assumes that higher level of per capita income leads to higher fertility rates and the per capita income growth at the "subsistence level" is zero. More recent conventional analyses on the fertility show the contrary prediction, higher level of per capita income implies a lower steady-state rate of population growth. However, this does not mean that the elasticities of demand for children are negative. As pointed out by Becker and Lewis [1973], even though the income elasticity of demand for children 
between fertility and income holds only when countries have a little human capital.

My analysis also shows similar result. Since the shadow price of quality $\pi_{q}$ varies positively with the fertility rate $n$, a decrease in $\pi_{q}$ would lower the fertility rate $n$. In the course of economic development, per capita income rises and the shadow price of quality falls. Although income effect in the equation (20) is positive, the net effect from higher income and lower shadow price of quality is then an empirical matter. That is, the "observed" elasticities of demand for children may be negative, despite the "true" elasticities are positive. Theoretically, the equation (20) does not rule out the situation that fer tility rises as economy grows.

The shadow price of quantity $\pi_{N}$ does not show a clear relation with the fertility. The $\pi_{N}$ in the denominator shows a negative relation with $n$, while $\pi_{N}$ in the numerator has a positive effect on $n$, unless the expression $\left(w+r k-\pi_{c} c\right)$ is negative. Thus the net effects of the shadow price of quantity are ambiguous when per capita income is greater than consumption. $M$ uch of the ambiguity in the effects of $\pi_{N}$ over the fertility rate in the equation (20) stems from a lack of explicit linkage between the value of human time and costs of raising children in the family budget constraint. One of the important sources that contributes to increasing the shadow price of quantity and lowering the shadow price of quality is the rising value of human time as a result of economic development. The value of human time is the major cost of raising children for a given level of quality per child. Taking into account this aspect of the fertility choice, the positive income effect of the demand for children would be further offset by rising costs. It is then reasonable to perceive that the net effect of $\pi_{N}$ over $n$ is negative.

The result also shows a positive relation between fertility and altruism per child. This implication is consistent with standard fertility analysis when 
ence rate and raises fertility. Since the path of the per capita consumption is negatively related to the rate of time preference, a higher altruism per child is associated with higher future consumption. Higher altruism per child and lower time preference rate is related to greater investments per child and could lead to a substitution of quality for consumption in the transition. Thus demand for quantity and quality are both positively related to altruism. Although parental altruism is one of the determinants of fertility choice, this paper will not further explore its impacts on fertility. The formation and change of parental altruism are still ignored in most literatures of the economic approach to fertility. N onetheless, if again the interaction between $\pi_{q}$ and $\pi_{N}$ is included, a higher altruism per child can increase the demand for children in the form of increased total quality.

\section{Output Growth and the Shadow Price of Quality}

In the course of modern economic development, fertility rate falls and quality per child measured by education and health increases in most industrial and other rapid growing economies. As discussed in Section II, shadow price of quality plays a key role in the transition toward a lower rates of fertility. A decrease in the shadow price of quality is equivalent to an increase in the rates of return on investment in human capital. Increase in the rates of return in to human capital raise expenditure on $q$ and require a postponement of entering labor market. This section extends the analysis to include the investment in human capital and economic growth.

Assuming that all the expenditure on $q$ is directly related to the accumulation of human capital, $h=h(q)$, and the total human capital stock is $H=h N$. Since the alternative uses of parental time and effort can be spent on work and educating children, the model assumes that the proportions of these 


$$
y=A k(u h)^{1-},
$$

where $\mathrm{y} \equiv \mathrm{Y} / \mathrm{N}$ and $\mathrm{k} \equiv \mathrm{K} / \mathrm{N}$. Then the accumulation of $\mathrm{k}$ can be written as

$$
\dot{k}=A k(u h)^{1-}-\left({ }_{q} q / N\right)-{ }_{N} n-{ }_{c} C
$$
By introducing the effort or current time allocation, the accumulation
human capital can be represented by

$$
\dot{H}=(1-u) H,
$$

where $(1-u)$ is the effort devoted in the accumulation of human $d_{\text {ital, and }}^{\text {(24) }}$ $\delta$ the efficiency of the effort used in the production of human capital. If all effort is used in the production of output $(u=1)$, then no effort $(1-u=0)$ is used in the accumulation of human capital and $\mathrm{H}=0$. Therefore the opportunity cost of accumulating human capital, such as on-the-job training and schooling, is explicitly expressed as the foregone output production. The evolution of the per capita stock of human capital is

$$
\dot{\mathrm{h}}=[(1-\mathrm{u})-\mathrm{n}] \mathrm{h},
$$

Using the equations (23), (25), and the utility function, the growth rate of output can be solved from the system. Note that the system now includes three state variables and four control variables. A new current-value Hamiltonian can be expressed as:

$$
\begin{aligned}
H_{c}= & \frac{1}{1-}\left(\mathrm{n} \mathrm{N}^{1-} \mathrm{cq}\right)^{1-}+{ }_{1}(\mathrm{nN}) \\
& +{ }_{2}\left[\text { Ak }(u h)^{1-}-\left({ }_{q} \mathrm{q} / \mathrm{N}\right)-{ }_{N} \mathrm{n}-{ }_{\mathrm{c}} \mathrm{c}\right]+{ }_{3}[(1-\mathrm{u})-\mathrm{n}] \mathrm{h} .
\end{aligned}
$$

The growth rate of the per capita output can be derived from the model (Appendix A):

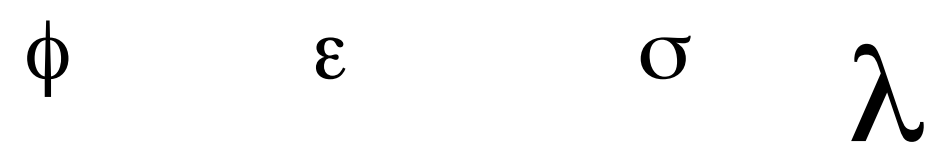

$\alpha$

$\alpha$ 


$$
\frac{\dot{y}}{y}=\frac{(1-)\left(\mathrm{n} \mathrm{N}^{1-} \mathrm{q}\right)(\dot{q} / \mathrm{q})-}{(1-) \mathrm{Ak} \mathrm{u}^{1-} \mathrm{h}^{-}(\mathrm{dh} / \mathrm{dq})-(1-) \Delta}
$$

In this expression, a lower shadow price of quality $\pi_{q}$ is associated with faster pace of the rate of economic growth, holding other variables constant. The effect of a change in fertility rate $n$ over the per capita growth rate, however, does not show a clear-cut direction. Larger $n$ tends to raise per capita output growth, while the resulting larger $\mathrm{N}$ in the denominator lowers the per capita growth.

The ambiguous relation between fertility and economic growth rate can be further discussed in terms of the equation (20). Since the equation (20) shows that lower shadow price of quality $\left(\pi_{q}\right)$ implies a lower fertility rate $n$, while the equation (27) shows that lower shadow price of quality is associated with faster per capita output growth rate. Thus there is a negative relation between economic growth rate and equilibrium fertility. This relation can be shown in Figure 1:

\section{Figure 1}

\section{Equilibrium Fertility and Economic Growth}

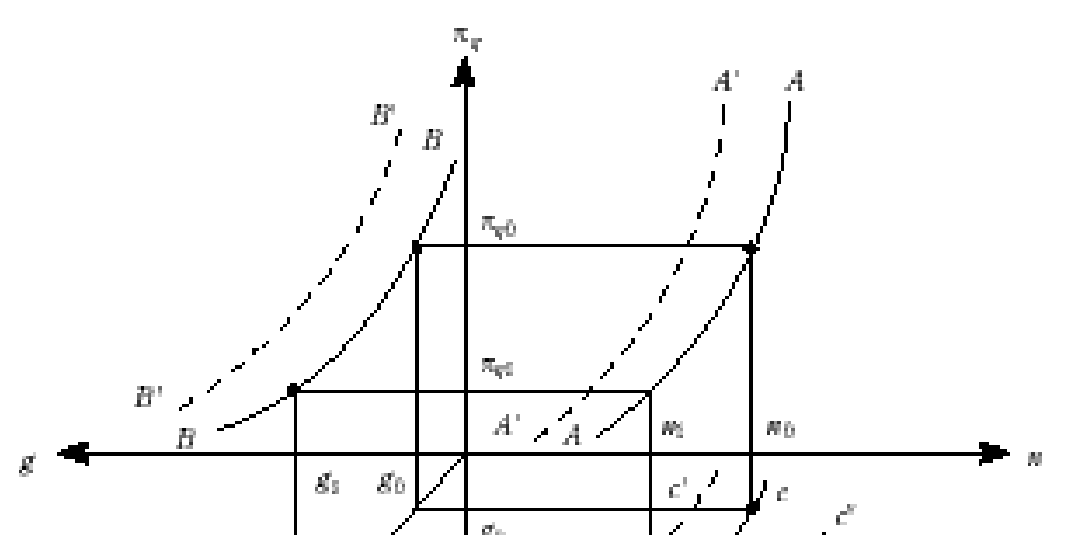


The positive relation between $\pi_{q}$ and $n$ represented by the curve AA in quadrant $\mathrm{I}$, while the negative relation between $\pi_{\mathrm{q}}$ and economic growth rate $g$ is drawn in quadrant II (curve BB). Through a $45^{\circ}$ line in quadrant III, the relation between $n$ and $g$ is shown in quadrant IV (curve CC). A lower equilibrium fertility rate $\mathrm{n}_{1}$ (compared with $\mathrm{n}_{0}$ ) is associated with a higher economic growth rate $g_{1}$ (compared with $g_{0}$ ). From the figure we can see that the relation between $\mathrm{g}$ and $\mathrm{n}$ is linked through the shadow price of quality $\pi_{q}$. Since $\pi_{q}$ is determined by other factors in the economy such as the opportunities and rates of returns in investment in human capital, a family planning program that reduces the fertility $n$ for all levels of $\pi_{q}$ shifts the AA curve leftward to $A^{\prime} A$ '. A new $n \pi_{q}$ schedule will also cause $C C$ curve move inward to $C^{\prime} C^{\prime}$. Consequently, a policy that reduce $n$ may not necessarily raise economic growth $\mathrm{g}$.

Figure 1 can also explain the situation where $n$ and $g$ move in the same direction. For example, increase in the altruism per child and hence a lower time preference rate would raise per capita output growth rate in the equation (27), while a higher altruism per child (lower time preference) raises fertility in the equation (20). Hence a positive linkage between equilibrium per capita output growth and fertility is al so feasible in the system. In figure 1 , a lower time preference causes higher growth rate is equivalent to shifting BB curve outward (to the left) and thus causing a rightward shift of CC curve. It would imply either a higher per capita output growth rate for any given fertility or a higher fertility and economic growth occur at the same time. The positive relation is therefore feasible when CC curve is moving toward the right. The same projection applies when other factors - say, technological progress - moves B B curve outward. In short, the analysis shows that the although for any given set of CC curve, higher $n$ is associated with lower $g$, but the relation can not be manipulated by artificially bringing 
between quality and quantity, the equation (27) shows that lower shadow price of quality and thus higher rates of return on human capital investment raises the demand for $q$ relative to $n$. An increase in investments on the quality of children induced by a lower shadow price $\pi_{q}$ increases the education expenditure per child, which is consistent with higher growth rate in per capita output. Thus the relation between fertility and economic growth rate is dependent on a set of variables and parameters which determines shadow price of quality. Bar ro and Becker [1989] derives the relation that a higher steady-state per capita growth rate is associated with a lower growth rate of population. In their model, higher per capita growth also raises real interest rate, while a higher real interest rate lowers fertility. Thus the negative relation between per capita growth rate and fertility holds only if the positive association between per capita growth rate and real interest rate is sufficiently weak. ${ }^{8}$

Although the Malthusian theory had become outdated long before the end of the nineteenth century, the theory has revitalized in recent decades in various forms with or without the name of the neo-M althusianism. There still seems to be a great number of people and policy makers believing that population growth has been an obstacle to economic growth in less developed countries. There is a common notion among those who fear population growth will eventually thwart the growth of per capita income: "Increasing fertility of the soil and reducing the fertility of human beings" $\langle$ Meier [1989]).9 M y analysis shows that if the effects of the price of quality dominate others, a fertility does show a negative relation with economic growth. However, through the endogenous decisions of fertility choice and investment in quality of children, the result does not necessarily imply lower fertility would cause faster pace of growth, unless high costs of fertility have been a major factor in determining the fertility and the size of family. Rosen- 
zweig [1990] shows that the costliness of fertility control only plays a minor role in inhibiting human capital investment.

Does difference in the parental altruism play an important role in the cross-country comparison of economic growth? According to the model, if we holds shadow price of quality constant and assume that there are no government subsidies and tax on fertility and education, then observed differences in fertility and economic growth can result from differences in altruism. Easterlin [1983] believes the preference and thus the parental altruism changes over time, and the demand for children is heavily influenced by parents' tastes. As discussed in previous section, a change in parental altruism changes fertility. But the knowledge of the formation of altruism is still in its preliminary stage in economics, there are still insufficient theories and evidence that can be used to further analyze its interrelations with other factors in the model. Without using difference in altruism as a source to account for the declining fertility, the model of this paper can generate similar implications that fertility choice change as economic conditions changes.

Families of poorer countries invest a much smaller per capita amount in children than do families of richer countries, although the total investments in terms of percentage of family income may not be lower in poorer countries. Presumably this reflects a much higher shadow price of quality of children in less developed countries. Or alternatively, it also reflects a higher rates of return from having more "quantity" of children in less developed countries, as described by T.W. Schultz [1973]: "Children are in a very important sense the poor man's capital." The opportunities of investments and rates of return to education increased rapidly in Taiwan and other fast growing East Asian economies since 1960s. A secular decline in fertility rates not only reflects decreasing shadow price of quality, but also represents intentional efforts in pursing the maximum returns of investment on 
The shadow price of quality plays a key determinant in linking the fertility change and the growth of per capita output. The result shows explicitly that the income effect of demand for children is positive in the equilibrium path of fertility. Thus on the one hand the model bears M althusian implication that children are normal goods; on the other hand, the "observed" decline in fertility does not represent the "true" elasticities of demand for children. Since the shadow price of quality varies positively with fertility, a sufficiently large effect of this linkage can bring a negative relation between per capita income and fertility.

The relation between fertility and economic growth can not be signed directly from the balanced growth path. This is because equilibrium fertility varies negatively with the rate of time preference. Thus a higher fertility is consistent with lower time preference and higher savings rate, which is consistent with a higher rate of economic growth. However, a lower shadow price of quality is consistent with both lower fertility and faster pace of per capita output growth. A positive link between fertility and economic growth is derived through the impacts of the shadow price of quality. In order to highlight the role of the shadow price of quality in linking between fertility and growth, a graph (figure 1) is used to summarizes these interdependent effects on economic growth and fertility. Whether there exists a positive or negative link between fertility and growth depends on whether the set of variables and parameters that determine the relations between $\pi_{q}$ and $n$ and $\pi_{q}$ and $g$ are stable. If all these variables are not changing, then the observed relations between $\mathrm{n}$ and $\mathrm{g}$ would be negative.

Since a policy that reduces fertility itself does not necessarily cause a faster growth in per capita income if the factors defining the relations between $\mathrm{n}$ and $\pi_{\mathrm{q}}$ do not change, a more cautious way to accept warnings on population explosion is required. In addition to changing relations between 
growth and fertility specified in the model of this paper.

\section{References}

Barro, Robert and Gary S. Becker [1989], "Fertility Choice in a M odel of Economic Growth," E conometrica, 57, No. 2 (M arch); pp. 481-501.

Becker, Gary S. [1993a], A Treatise on the Family (enlarged ed.) (1st ed. 1981), Cambridge: Harvard University Press.

Becker, Gary S. and Gregg H. Lewis [1973], "On the Interaction between the Quantity and Quality of Children," Journal of Political Economy, Vol. 81, no. 2 (part 2); pp. 279-288.

Becker, Gary S. and Robert B arro [1988], "A Reformulation of the Economic Theory of Fertility," Q uarterly Journal of E conomics, 103; pp. 1-25.

Becker, Gary S., M urphy, Kevin M ., and Tamura, Robert [1990], "Human Capital, Fertility, and Economic Growth," Journal of Political Economy 98 (October); pp. 12-37.

Ben-Porath, Yoram [1967], "The Production of Human Capital and the Life Cycle of Earnings," Journal of Political Economy 75, No.4, part 1 (August); pp. 352-65.

De Tray, Dennis N. [1973], "Child Quality and the Demand for Children." Journal of Political Economy 81 (2, pt.2); pp. 70-95.

Easterlin, Richard [1983], "M odernization and Fertility: A Critical Essay," in Determinants of Fertility in Developing Countries, Vol.2, R.Bulatao and R.Lee, eds. New York: Academic Press, 1983; p. 562-586.

Eckstein, Zevi and Kenneth I. Wolpin [1985], "Endogenous Fertility and Optimal Population Size," Journal of Public Economics 27 (J une); pp. 93-106.

Lucas, Robert E. [1988], "On the Mechanics of Economic Development," 
Razin, Assaf and Ben-Zion, Uri. [1975], "An Intergenerational M odel of Population Growth," American E conomic Revi ew 65 (December); pp. 92333.

Romer, Paul M . [1986], "Increasing Returns and Long-Run Growth," Journal of Political Economy 94; pp. 1002-37.

Romer, Paul M. [1990], "Endogenous Technological Change," Journal of Political Economy 98, no. 5, pt. 2 (October); pp. 71-102.

Rosen, Sher win [1983], "Specialization and Human Capital," Journal of Labor Economics 1; pp. 43-49.

Rosenweig, Mark R. [1998], Population Growth ad Human Capital Investment: Theory and Evidence, Journal of Political Economy, no. 5, pt. 2 (October); pp. 38-70.

Sah, Raaj K. [1991], "The Effects of Child M ortality Changes on Fertility Choice and Parental Welfare," Journal of Political E conomy, vol 99, no.3 (J une); pp. 582-606.

Schultz, Theodore W. [1960], "Capital Formation by Education," Journal of Political E conomy 68; pp. 571-83.

Schultz, Theodore W. [1973], "Fertility and Economic Values," in Economics of the Family, T.W. Schultz, ed. Chicago: University of Chicago Press, 1973; pp. 3-22.

Solow, Robert M . [1957], "Technical Change and the Aggregate Production Function," Review of Economics and Statistics 39 (August); pp. 312-20.

Uzawa, Hirofumi [1965], "Optimal Technical Change in an Aggregate M odel of Economic Growth," International E conomic Revi ew 6 (J anuary); pp. 18-31.

Willis, Robert J . [1973], "A New Approach to the Economic Theory of Fertility B ehavior," Journal of Political Economy 81 (2, pt. 2); pp. 14-64. 


$$
\begin{aligned}
& \left(\mathrm{n} \mathrm{N}^{1-} \mathrm{c}\right)^{1-} \mathrm{q}^{-}=-{ }_{2}\left[(1-) A k u^{1-} \mathrm{h}^{-} \frac{\mathrm{dh}}{\mathrm{dq}}-\left({ }_{\mathrm{q}} / \mathrm{N}\right)-\frac{\mathrm{N}}{\mathrm{q}} \mathrm{n}\right] \\
& -3[(1-u)-n] \frac{d h}{d q}, \\
& \left(\frac{\mathrm{n}}{\mathrm{n}}\right)\left(\mathrm{n} \mathrm{N}^{1-} \mathrm{cq}\right)^{1-}=-{ }_{1} \mathrm{~N}+2\left(\frac{\mathrm{q}}{\mathrm{n}} \frac{\mathrm{q}}{\mathrm{N}}+\mathrm{N}\right)+{ }_{3} \mathrm{~h} . \\
& { }_{2}(1-) \mathrm{Ak} \mathrm{h}^{1-} \mathrm{u}^{-}={ }_{3} \mathrm{~h} .
\end{aligned}
$$

Since the evolution of costate variables are

$$
\begin{aligned}
& i_{1}=-\frac{\mathrm{H}_{\mathrm{c}}}{\mathrm{N}}+{ }_{1}=-\left(\frac{1}{\mathrm{~N}}\right)\left(\mathrm{n} \mathrm{N}^{1-} \mathrm{cq}\right)^{1-}(1-)-{ }_{1} \mathrm{n}+{ }_{1} \text { (A.5) } \\
& \dot{2}_{2}=-\frac{\mathrm{H}_{\mathrm{c}}}{\mathrm{N}}+{ }_{2}=-{ }_{2}(1-) \mathrm{Ak}^{-1}(\mathrm{uh})^{1-}+{ }_{2},
\end{aligned}
$$

and

$$
{ }_{3}=-\frac{\mathrm{H}_{\mathrm{c}}}{\mathrm{h}}+{ }_{3}=-{ }_{2}(1-) \mathrm{Ak}^{1-} \mathrm{h}^{-}-{ }_{3}[(1-\mathrm{u})-\mathrm{n}]+{ }_{3} \text { (A.7) }
$$

From the above equations and the conditions that all costate variables grow at the same rate at steady state, the following relations hold:

$$
\begin{aligned}
& (1 / N)\left(\mathrm{n} \mathrm{N}^{1-} \mathrm{Cq}\right)^{1-}(1-)+\mathrm{n} \\
& =\left(\frac{2}{3}\right)(1-) \mathrm{Ak} \mathrm{u}^{1-} \mathrm{h}^{-}+(1-\mathrm{u})-\mathrm{n},
\end{aligned}
$$

and

$$
\begin{aligned}
(1-) \mathrm{Ak}^{-1}(\mathrm{uh})^{1-} & =\left(\frac{2}{3}\right)(1-) \mathrm{Ak} \mathrm{u}^{1-} \mathrm{h}^{-} \\
& +[(1-\mathrm{u})-\mathrm{n}] .
\end{aligned}
$$

From the enuations (A.1). the exnrecsion of the arowth rate of $\lambda_{2}$ can he 
the equation (A.10) becomes

$$
\frac{2}{2}=(1-)\left(\mathrm{n} \mathrm{N}^{1-} \mathrm{q}\right)\left(\frac{\dot{n}}{\mathrm{n}}+\frac{\dot{q}}{\mathrm{q}}\right)-[(1-u)-\mathrm{n}] .
$$

Also from the equations (A.1) and (A.2), we get

$$
\frac{2}{3}=-\frac{[(1-u)-n](d h / d q)}{c(c / q)+(1-) A k u^{1-} h^{-}(d h / d q)-\left(2_{q} / N\right)}
$$

From the equation (A.7) and (A.11), the following relations hold:

$$
\begin{aligned}
& -\frac{2}{3}(1-) A k u^{1-} h^{-}-[(1-u)-n]+ \\
& \quad=(1-)\left(n^{1-} N^{1-}\right)\left(\frac{\dot{n}}{n}+\frac{\dot{q}}{q}\right)-[(1-u)-h] .
\end{aligned}
$$

Substituting the equation (A.12) into the above expression, the expression for the growth rate of per capita output can be shown as:

$$
\frac{\dot{y}}{y}=\frac{(1-)\left(\mathrm{nN}^{1-} \mathrm{q}\right)(\dot{\mathrm{n}} / \mathrm{n}+\dot{\mathrm{q}} / \mathrm{q})-}{(1-) \mathrm{Ak} \mathrm{u}^{1-} \mathrm{h}^{-}(\mathrm{dh} / \mathrm{dq})-(1-) \Delta}
$$

where

$$
\Delta=d(c / q)+(1-) A k u^{1-} h^{-}(d h / d q)-(2 q / N) .
$$

